\title{
BROTTSUTVECKLINGEN I SVERIGE 1980-2003 - TENDENSER OCH FÖRKLARINGAR
}

\section{AV GENERALDIREKTÖR JAN ANDERSSON}

Crime levels, actual as well as reported, have increased dramatically in Sweden since WW2. As in other countries, this increase is explained by major changes in urbanisation and economic development. However, there has been no continuous increase in crime since 1990. Theft-related crimes have actually decreased since then. The reasons for this are crime-specific, on the one hand, and structural, on the other. Like many other countries exhibiting similar crime trends, Sweden has suffered an economic stagnation. Nonetheless, the level of reported violent crime continues to increase, partly due to an increase in the consumption of alcohol (which primarily affects street violence) and partly due to an increase in the willingness to report violent crime (mainly among women and children).

Official reports concerning some forms of statistically infrequent crime - such as white-collar crime, environmental crime, and agitation of national or ethnic groups - are increasing very dramatically. An important explanation for the increase in official reports of these crimes relates to changing priorities and methods within the legal system. However, this does not mean that the actual levels of these crimes have not increased.

According to self-report surveys juvenile participation in theft-related crime is decreasing while juvenile violent crime remains relatively stabile. Overall, however, juvenile crime is on the decline."

\section{Om statistiken som beskriver utvecklingen}

För precis 20 år sedan publicerades i denna tidskrift en artikel som beskrev brottsutvecklingen i Sverige under perioden 1950 - 1982 (Svensson, 1984). I artikeln redogjordes inledningsvis för de svagheter som är förenade med de uppgifter som vi vanligen använder för att beskriva brottsutveckling, dvs. statistiken över anmälda brott. De problem som då lyftes fram är desamma som diskuteras i dag: Benägenheten att anmäla ett brott varierar mellan olika typer av brott och kan också variera mellan olika grupper av personer och mellan olika tidsperioder. De rättsvårdande myndigheternas prioriteringar spelar också in, särskilt för de brott som vi ibland kallar offerlösa. Slutsatsen är att anmälningsstatistiken måste tolkas med försiktighet, fallgroparna är många.

\footnotetext{
"Title in English: Crime in Sweden 1980 to 2003: Trends and Explanations. Original in Swedish.
} 
Några alternativa eller kompletterande serier av det slag som Svensson efterlyste i sin artikel för 20 år sedan har inte utvecklats i Sverige. I vart fall inte sådana som förekommer i bland annat England och USA, dvs. omfattande offerundersökningar som löpande belyser utsattheten för olika typer av brott. Visst förekommer frågeundersökningar även i Sverige, men än så länge är de inte av det slaget att de är tillräckliga för att utgöra underlag för att mer i detalj analysera brottslighetens omfattning och utveckling.

I jämförelse med situationen för två decennier sedan är det dock min uppfattning att underlaget för att tolka anmälningsstatistiken blivit bättre. Det finns numera kompletterande serier om utsattheten för brott, om än bland avgränsade grupper av befolkningen och för enskilda brottstyper. Det har också, sedan mitten av 1990-talet, utvecklats en serie av frågeundersökningar som belyser de svarandes deltagande i brottslighet. Visserligen handlar det om en begränsad del av befolkningen, men en mycket central grupp, nämligen ungdomar i 15-årsåldern. Till detta skall läggas att antalet specialundersökningar om utvecklingen av särskilda brottstyper har blivit fler. Det har inte bara inneburit att kunskapen om utvecklingen av just dessa brottstyper har ökat, utan också att kunskapen om de faktorer som bestämmer mörktalets storlek har fördjupats. Möjligheten att tolka anmälningsstatistiken har således blivit bättre.

Vidare har under åren kunskapen ökat om de "fel och brister" som är förknippade med systemen för inrapporteringar av brottsliga händelser. Fel och brister sätts här inom citattecken för att understryka att mycket av det som kan uppfattas som fel i statistiken egentligen inte är fel, utan en följd av att polisstatistiken mer är ett ärendehanteringssystem än något som byggts upp för att visa hur det är ställt med brottsligheten och utvecklingen av densamma.

Den följande framställningen bygger således i huvudsak på statistiken över antalet anmälda brott. Bilden kompletteras där så är möjligt med andra typer av data. I figurerna anges det totala antalet anmälda brott per år, för olika brottskategorier. Det kan därför finnas anledning att något beröra frågan om brottsnivåerna: Vid internationella jämförelser av statistik över anmälda brott hamnar Sverige oftast mycket högt på listan. En central förklaring till detta är att Sverige har en i förhållande till många andra länder extensivt, eller om man så vill ambitiöst, upplagd brottsstatistik. Dels innehåller den officiella statistiken i Sverige i högre utsträckning än i många andra länder s.k. bagatellbrott, dels innebär de svenska principerna för antalsräkning av brott att alla enskilda brott räknas, även om de riktats mot samma offer och begåtts inom en begränsad tidsperiod. Dessa, och flera andra skillnader mellan sätten att statistikföra brott, leder till att nivåerna inte är jämförbara mellan olika länder. Därför fokuseras i det följande på utvecklingen och inte de absoluta nivåerna. 


\section{Om utvecklingen av anmälda brott 1980-2003}

År $2003^{1}$ anmäldes strax över 1,25 miljoner brottsliga händelser till polisen. Motsvarande antal år 1980 var knappt 930000 brott. Då som nu domineras anmälningsstatistiken av stöldbrotten (8 kap BrB), år 2003 utgjorde de 53 procent och 198056 procent av samtliga anmälningar. Andelen våldsbrott (3 kap BrB) är liten, men har ökat under den studerade perioden, från 2,9 till 5,4 procent av samtliga brott.

Som framgår av figur 1 är det inte fråga om en jämn ökning av antalet anmälda brott från 1980 och framåt, utan utvecklingen kan delas in i två perioder. Den första perioden består av en ökning fram till år 1990, en utveckling som i stort är en fortsättning på den brottstillväxt som kunnat konstateras sedan år 1950. Antalet fler anmälda brott under perioden 1980-1990 (ca 290000 brott) är i det närmaste lika stor som ökningen decenniet innan (270 000 brott). Den andra perioden, med början år 1990, karakteriseras av vissa mindre upp- och nedgångar runt en förhållandevis stabil nivå. Mellan år 1990 och år 2003 stannar ökningen på strax under 32000 brott.

Figur 1. Anmälda brott, åren 1980-2003

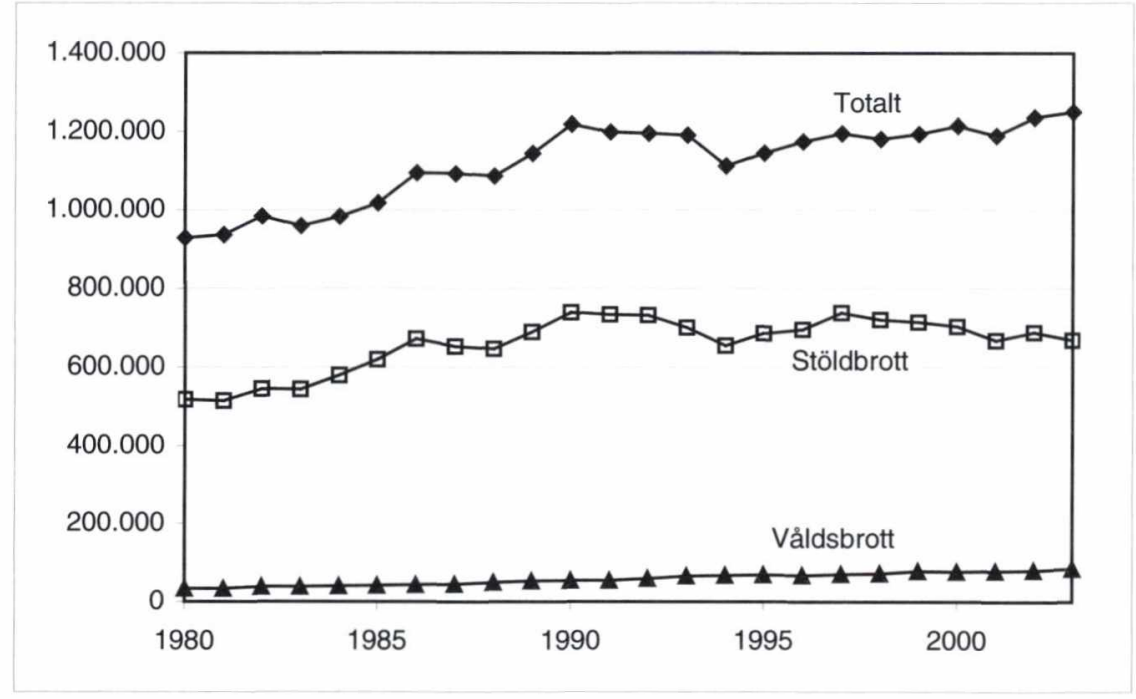

\footnotetext{
${ }^{1}$ Här och i det följande presenteras preliminära siffror för år 2003. Erfarenhetsmässigt skiljer sig de definitiva från de preliminära med endast några tiondelar av en procent.
} 
Trendförändringen - om man nu vill kalla det så - är tydligast för stöldbrottsligheten. Det högsta antalet anmälda stöldbrott inträffade under år 1990, därefter har antalet brott minskat. Antalet anmälda stöldbrott är närmare 72000 färre år 2003 än vad de var år 1990. Utvecklingen avseende våldsbrott är den motsatta. Antalet anmälningar har ökat under hela den studerade perioden och det $\mathrm{i}$ en närmaste jämn takt. År 1980 uppgick antalet våldsbrottsanmälningar till strax under 27000 och år 2003 till nästan 69 000, dvs. en ökning med hela 165 procent.

Varför denna ökning och därpå följande avmattning vad gäller stöldbrott? Ökningen av brottsligheten sedan efterkrigstiden ${ }^{2}$ har kopplats samman med olika större samhällsförändringar, som ett ökat utbud av varor som dessutom inte skyddas lika mycket som tidigare. Den sociala kontrollen har minskat i takt med att samhället har urbaniserats och att rörligheten har blivit större. Allt fler bostäder står tomma utan tillsyn under dagarna och i butikerna är det allt färre anställda som skall kontrollera ett allt större antal varor. Familjens och kyrkans roll har förändrats, vilket också skolans funktion har. Allt detta och mer därtill har inneburit - för att använda Cohen\&Felsons (1979) begreppsapparat - att antalet "motiverade gärningsmän" allt oftare sammanstrålar i tid och rum med "lämpliga objekt" som är i frånvaro av "kapabla väktare".

Motsvarande utvecklingen, dvs. en ökning följt av en utplaning av brottsligheten runt år 1990, är vid handen i ett stort antal andra europeiska länder, bland annat Tyskland, England, Holland, Finland och Danmark (Westfeldt, 2001). I vart och ett av dessa länder - inklusive Sverige - förekommer nationsspecifika förklaringar, men även en som är i stort sett gemensam för alla dessa länder, nämligen att stöldbrottens utveckling delvis hänger samman med utvecklingen av konjunkturerna. Stagnationen av brottsligheten skulle alltså förklaras av den ekonomiska stagnationen, som för flertalet länder i Europa inträffade runt decennieskiftet 1989/1990. De nationsspecifika förklaringarna är ofta förknippade med vissa enskilda brottstyper, vilka för Sveriges del behandlas senare i texten.

Varför har då våldsbrotten en så annorlunda utvecklingskurva jämfört med den för stölderna? De generella förklaringarna här kretsar kring två faktorer. Den ena är den ökande anmälningsbenägenheten, vilken i sin tur förknippas med att omsorgen om den fysiska integriteten spelar en allt större roll i ett samhälle som vårt. Avståndstagandet gentemot våld som konfliktlösningsmetod anses ha ökat successivt och därmed benägenheten att anmäla även mindre allvarligt våld. Våldsoffrens ställning har också stärkts, dels genom lagstiftningsåtgärder, dels

\footnotetext{
${ }^{2}$ Egentligen inleddes, mätt med lagföringsstatistik, ökningen under 1920-talet. Anmälningsstatistik för hela riket finns dock först från år 1950.
} 
genom uppkomsten av moderna sociala rörelser som kvinnojourer och brottsofferjourer (Kühlhorn, 2001). Den andra faktorn är den ökande alkoholkonsumtionen, inte minst i och kring krogmiljöer, vilket anses förklara en stor del av ökningen av det så kallade gatuvåldet. Att hushållens ekonomi inte utvecklats $\mathrm{i}$ samma takt som under tidigare decennier har inte hindrat allt fler att dricka alkohol allt mer och allt oftare.

\section{Om utvecklingen av vissa stöldbrott}

Antalet anmälda stöldbrott har således minskat sedan 1990-talets början. Utvecklingen ser dock olika ut för olika brottstyper och förklaringarna till utvecklingen - utöver den för så många länder gemensamma generella förklaringen: ekonomisk stagnation - kan också variera mellan olika brottstyper. Brottsförebyggande insatser brukar lyftas fram som förklaringar till att till exempel bostadsinbrotten minskat. År 2003 anmäldes strax över 17000 sådana brott mot över 24000 år 1994. En bidragande orsak anses vara de brottspreventiva åtgärder som vidtagits i många bostadsområden, t.ex. i form av säkerhetsdörrar, portlås, fler och bättre lås och larm. I vissa bostadsområden anses ökad upptäcktsrisk genom systematisk grannsamverkan ha bidragit till minskad utsatthet.

\section{Bilrelaterad brottslighet}

Med bilrelaterad brottslighet avses i det följande tillgrepp av bil samt stöld ur och från motordrivet fordon. Brottskategorin är mycket omfattande, de bilrelaterade brotten har under den studerade perioden årligen svarat för mellan 15 och 18 procent av samtliga anmälda brott. Ungefär två tredjedelar av dessa brottsanmälningar avsåg stöld ur och från bil. Som framgår av figur 2 nådde antalet brott sin högsta nivå år 1990, för att snabbt minska i antal och därefter öka igen.

Trots att antalet anmälda biltillgrepp i dag är betydligt högre än för 25 år sedan, är den relativa risken att utsättas för ett sådant brott ungefär densamma. Skälet till att brottsutvecklingen beträffande bilar ser ut som den gör hänger således samman med den förändrade tillfällesstrukturen. Antalet stöldbegärliga objekt har ökat kraftigt sedan år 1980 och följaktligen också antalet brott. Om brottsnivåerna sedan dess relateras till antalet bilar i trafik är förändringarna betydligt mindre. På det hela taget överensstämmer förändringarna i statistiken över bilrelaterade brott med den ekonomiska konjunkturen (Blixt, 2001). Vid ekonomiskt sämre tider ställer många av sina bilar, för att på så sätt undgå olika typer av försäkringskostnader m.m. 
Figur 2. Anmälda bilrelaterade brott, åren 1980-2003

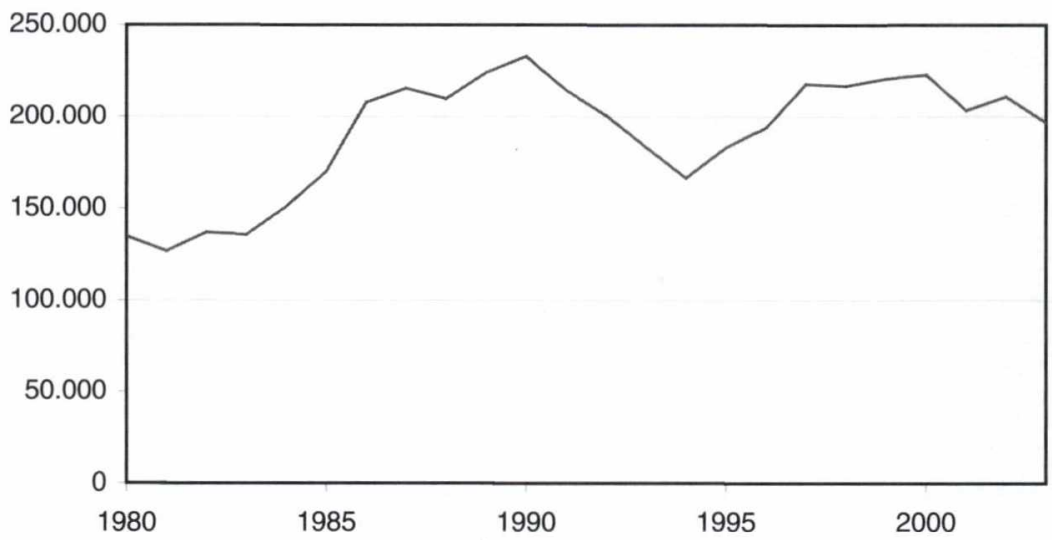

Utvecklingen av den bilrelaterade brottsligheten kan således delvis förklaras med att antalet "lämpliga objekt" som "den motiverade gärningsmannen" sammanstrålar med, har förändrats över tid. Till detta skall läggas att en del av förklaringen till nedgången av framför allt biltillgreppen sedan år 1997 (en minskning med hela 20 procent) är att "de kapabla väktarna" har ökat. Bilparken byts successivt ut mot bilar som det i praktiken är omöjligt att stjäla utan tillgång till bilnyckel, och insatserna framför allt på lokal nivå för att förebygga bilbrottsligheten, t.ex. genom säkrare bilparkeringar, har ökat i omfattning.

\section{Om utvecklingen av vissa våldsbrott}

Våldsbrottsligheten har, till skillnad från stöldbrottsligheten, haft en i det närmaste kontinuerlig ökningstakt under hela den studerade perioden. Utvecklingen ser dock olika ut för olika typer av våldsrelaterade brott och förklaringarna till respektive utvecklingskurva kan också variera. Utomhusvåldet mellan obekanta ökar, enligt undersökningar beroende på ökad alkoholkonsumtion och ett förändrat konsumtionsmönster. Antalet anmälda personrån har under den studerade perioden ökat mycket kraftigt, vilket huvudsakligen hänger samman med att brottskategorin allt mer kommit att bli ett utpräglat ungdomsbrott. Särskilt kraftig har ökningen varit i storstäderna och vad som särskilt uppmärksammats under de senaste åren är det ökade inslaget av mobiltelefonrån. Likaså har, sett över hela perioden, butiksrånen ökat mycket kraftigt. Bank- och postrånen uppvisar en helt annan utveckling. Antalet sådana rån har minskat, vilket bland annat förklarats 
av ett ökat säkerhetstänkande och att antalet bank- och postkontor har minskat. År 2003 anmäldes 92 sådana brott mot 226 brott år 1994.

I det följande ges en sammanfattande redovisning av trender och förklaringar beträffande två mycket olika former av våldsbrott; det dödliga våldet respektive våld mot barn och ungdomar.

\section{Det dödliga våldet}

År 2003 polisanmäldes 195 fullbordade mord, dråp, misshandel med dödlig utgång och barnadråp. Detta är en kraftig ökning jämfört med år 1980, då motsvarande antal var 135 brott. Polisstatistiken beträffande det dödliga våldet är dock inget bra mått på antalet personer som mördats eller på annat sätt fallit offer för dödligt våld i Sverige. Anledningen till detta är att ett dödsfall anmäls som dödligt våld så fort det finns en misstanke om brott. I den fortsatta rättsprocessen kan det visa sig att dödsfallet hade naturliga orsaker, men polisanmälningarna utgör ändå underlaget till brottsstatistiken.

För det dödliga våldet finns det dock kompletterande och alternativa dataserier. Den alternativa serien utgörs av Socialstyrelsens dödsorsaksregister som visar att antalet fullbordade fall av dödligt våld legat på en förhållandevis konstant nivå kring 100 fall per år, under de 30 senaste åren. Den kompletterande serien är resultaten av en noggrann kvalitetsstudie av kriminalstatistiken (Rying, 2003) för att avgöra det faktiska antalet fall av dödligt våld som polisanmälts i Sverige. Den senare serien ger vid handen att antalet fall legat förhållandevis konstant kring en nivå på strax under 100 brott per år.

Ökningen av antalet polisanmälningar, som är särskilt tydlig från senare delen av 1990-talet, kan delvis förklaras av att nya registreringsrutiner hos polisen medfört att dubbel- och felregistreringar blivit fler. En annan "felkälla" är att även brott som begåtts utomlands men som anmäls i Sverige, ingår i statistiken. Dessa anmälningar har ökat i antal.

Flertalet bedömare är överens om att det faktiska våldet har ökat i samhället men också att en ökad anmälningsbenägenhet har bidragit till att antalet registrerade brott ökar år från år. Den dominerande förklaringen till att det dödliga våldet av allt att döma har legat på en konstant nivå under 30 års tid, är de mycket kraftiga förbättringar som sjukvården varit föremål för under motsvarande period. Ambulanser är i dag inte endast en transporttjänst utan har också möjlighet att vidta sådana förstahandsåtgärder vid allvarliga skador att det signifikant ökar de utsattas chans att klara sig med livet i behåll.

\section{Våld mot barn och ungdomar}

Sedan år 1981 redovisas den polisanmälda misshandeln fördelat på kategorierna misshandel mot man, mot kvinna, mot barn 0-6 år respektive mot barn 7-14 år. 
Det går också av statistiken att avgöra om brottet begåtts av någon bekant till offret och om brottet begåtts inomhus eller utomhus.

Som framgår av figur 3 har antalet anmälningar avseende misshandel mot barn ökat mycket kraftigt sedan 1980-talets början. Ökningen under 1990-talet och framåt kan i det närmaste beskrivas som explosionsartad. Den procentuella ökningen mellan åren 1990 och 2003 är nämligen hela 172 procent (0-6 år) respektive 294 procent (7-14 år). För båda kategorierna är ökningen mest markant för barn som var bekant med gärningsmannen. Denna utveckling motsvaras naturligtvis inte av en ökning av det faktiska våldet, vilket ett flertal studier har kunnat konstatera (bl.a. BRÅ, 2000). Slutsatsen i Barnmisshandelskommitténs betänkande (SOU 2001:72) är att ökningen av den polisanmälda misshandeln mot barn beror på en ökad anmälningsbenägenhet, såväl när det gäller förskolebarn som barn i skolåldern. Sett över en längre tidsperiod än den som studeras här, drar Janson $(2001 ; 2004)$ slutsatsen att allt färre barn misshandlas nu än förr, vilket anses bero på ett medvetet arbete på bred front med lagstiftning, familjepolitik, attitydbearbetning och förebyggande arbete.

Figur 3. Anmälda misshandelsbrott mot barn, åren 1981-2003

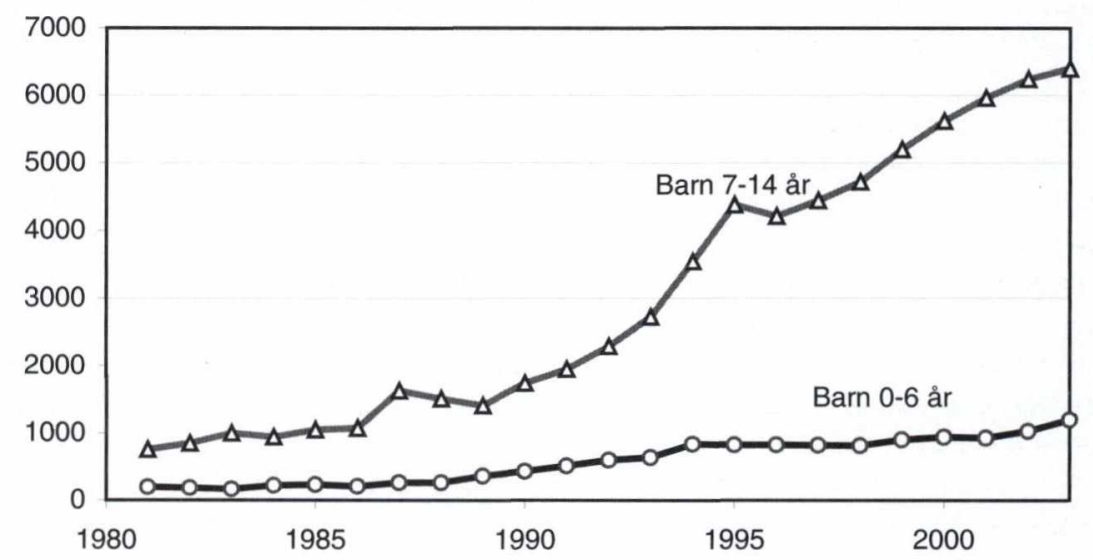

\section{Om utvecklingen av vissa andra brottstyper}

Brottsstatistiken är uppdelad i en stor mängd olika brottskategorier. Vissa av dessa innehåller förhållandevis få brott, men som är mycket uppmärksammade $\mathrm{i}$ den allmänna debatten, inte minst i massmedierna. Ett av dessa är kategorin hets mot folkgrupp (16 kap $8 \S \mathrm{BrB})$, bestämmelsen förbjuder i stort sett samtliga yttranden av rasistisk eller likvärdig innebörd, oavsett om det skett muntligt, i 
tryckt skrift eller i andra medier. Brottskategorin särredovisas i statistiken från och med år 1990. Under början av 1990-talet var antalet anmälningar mycket få, runt 100 per år. Från och med år 1996 har utvecklingen varit närmast dramatisk, antalet anmälningar under 2000-talet har legat på mellan ca 750 och 850 per år. Orsaken till denna ökning kan knappast hänföras till att det faktiska antalet brott har ökat i samma takt. I stället pekar bedömare på att den ökade uppmärksamheten på brott med rasistiska inslag medverkat till att benägenheten att anmäla sådana brott ökat. Av samma orsak har prioriteringarna och arbetssätten hos de rättsvårdande myndigheterna ändrats vilket har ökat sannolikheten för upptäckt. Samtidigt finns anledning anta att också den faktiska brottsligheten kan ha ökat. Produktionen av rasistiska och antisemitiska material ökade till exempel markant under 1990-talet, särskilt under dess senare del (Lööw, 2001). Under senare delen av 1990-talet minskade de anmälda skattebrotten, bokföringsbrotten och brotten mot borgenär. En viktig förklaring till nedgången av dessa ekonomiska brott var att skattemyndighetens revisioner minskat $\mathrm{i}$ antal och att konkurserna kraftigt gått ner efter det tidiga 1990-talets stora konkursuppgång. Det är vid revisioner respektive konkursförvaltningar som de vanligaste ekobrotten upptäcks (Korsell, 2001). Kriminalstatistiken speglar således mer de prioriteringar och de förändringar i arbetsmetoder som görs inom samhällets kontroll av företag. Uppskattningar av den svarta sektorn baserade på nationalräkenskaper m.m. ger vid handen att denna inte har ökat sedan början av 1980-talet (RSV, 2003).

De begränsade möjligheter att beskriva utvecklingen av antalet ekonomiska brott gör sig gällande också vid miljöbrottslighet. Under 1990-talets slut presenterade regeringen en strategi för bekämpning av miljöbrotten. Insatserna handlade om skärpt lagstiftning, samordning och samarbete, kompetenshöjning och effektivare organisation. Miljöbalken som trädde i kraft år 1999 är ett omfattande regelverk men också en tydlig markering av miljöfrågornas betydelse (Korsell, 2001b). Utvecklingen av antalet anmälda miljöbrott - som karakteriseras av kraftiga upp- och nedgångar - styrs i det närmaste helt av vilka kontrollinsatser som sätts in och vad som kontrolleras.

\section{Avslutning - om ungdomsbrottsligheten}

Ungdomsbrottsligheten ökar! Eller gör den det? Att studera ungdomsbrottslighetens utveckling kan göras på olika sätt. Ibland förekommer att serien beskriver utvecklingen av "brott som vanligtvis begås av ungdomar", ibland att analysen omfattar utvecklingen av brott där den större andelen av de registrerat misstänka är ungdomar. Till detta kan läggas beskrivningar av antalet misstänkta personer i yngre åldrar. Beroende på vilken metod som väljs, erhålls olika resultat. Varken 
anmälningsstatistiken eller annan kriminalstatistik är särskilt tillförlitlig när det gäller att beskriva utvecklingen av ungdomsbrottsligheten.

I det följande redovisas därför resultaten av en alternativ serie som beskriver utvecklingen av ungdomsbrottsligheten (BRÅ, 2003). Även den har sina brister, men utgör ett komplement till annan statistik. Det handlar om resultat från en serie av enkätundersökningar som genomförts vartannat år sedan år 1995, där skolelever i årskurs 9 (huvudsakligen 15 år gamla) bland annat tillfrågats om sitt eget deltagande i brottslighet under det senaste året. Mellan 5300 och 8200 elever har varje år anonymt besvarat enkäterna.

Undersökningarna visar att andelen elever som uppger att de begått någon form av brottslig handling under det senaste året har minskat. Nedgången är tydligast beträffande stöldrelaterade brott och gäller för såväl pojkar som flickor. För pojkarna har andelen som uppger att de begått någon form av stöld minskat från 73 till strax under 61 procent, medan motsvarande minskning för flickorna är från 59 till 49 procent.

Utvecklingen av ungdomar deltagande i våldsrelaterade handlingar är inte lika tydlig som för stöld. För skadegörelsebrott däremot är tendensen tydlig; andelen ungdomar som uppger att de under det senaste året deltagit i skadegörelserelaterade handlingar som vandalisering och klottring, har minskat.

Figur 4. Delaktighet i brottsliga handlingar de senaste 12 månaderna, efter kön och år. Ungdomar i 9: de årskursen.

\section{Pojkar}

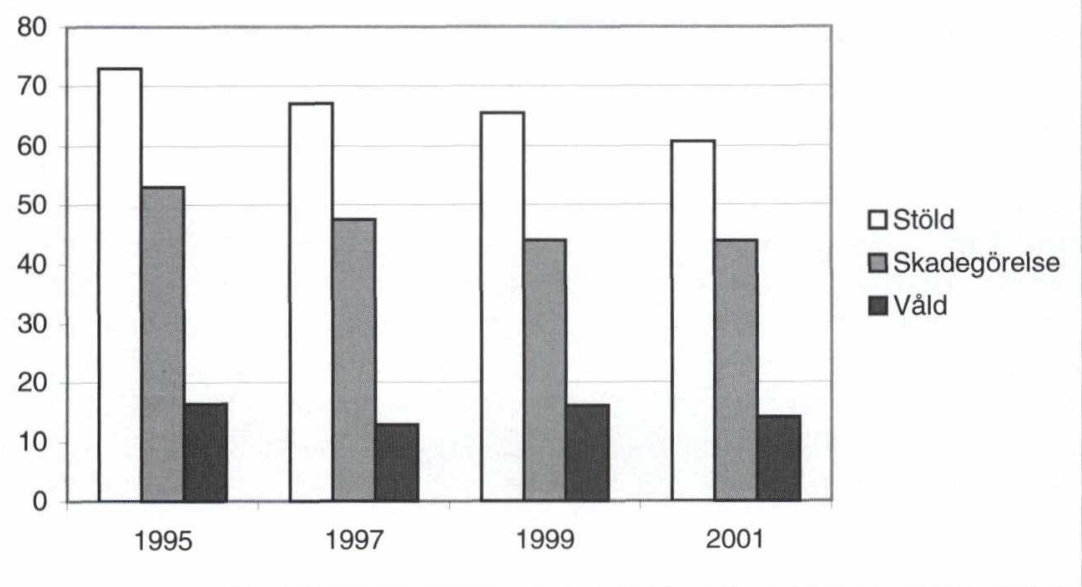




\section{Flickor}

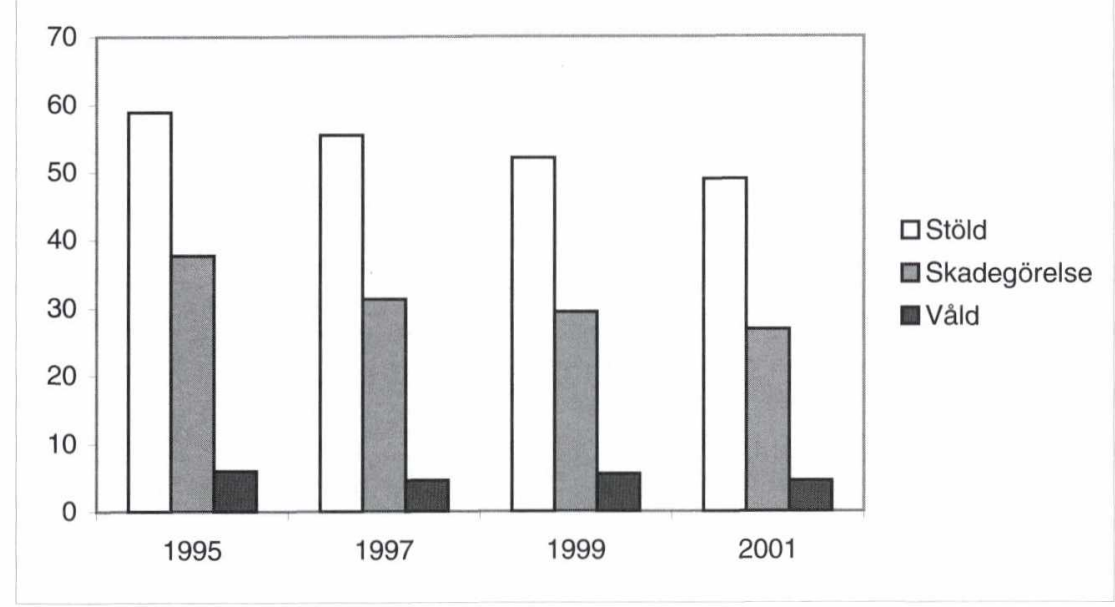

Tendenserna om en nedgång i ungdomars delaktighet i brottslighet förekommer i stort sett $i$ alla sociala grupper även om den är mer uttalad bland ungdomar med genomsnittligt mer socioekonomiskt gynnade uppväxtförhållanden (i undersökningen definierat som unga som hör till kategorierna högre tjänstemannahem, helsvensk bakgrund, ej splittrad familj respektive boende i villa).

Beskrivningen av brottslighetens utveckling i Sverige har som framgått i stort sett uteslutande byggt på uppgifter om antalet polisanmälda brott. Dessa data har tolkats i ljuset av befintliga andra serier av data och undersökningar av särskilda brottstyper. Inledningsvis hänvisades till att Svensson (1984) för 20 år sedan efterlyste kompletterande statistik för att bättre kunna bedöma den faktiska brottsutvecklingen. Tyvärr har detta önskemål inte infriats, varför det fortfarande ges stort utrymme för olika tolkningar. Och tolkas görs det, inte minst i massmedierna. Polisstatistiken utgör en aldrig sinande källa för den som vill hitta bevis på att brottsligheten ökar. Att ekobrotten ökar, liksom miljöbrotten och olika typer av hatbrott, det läser vi om i tidningarna mest varje dag. Likaså att allt fler barn misshandlas av sina föräldrar och att klottret har ökat dramatiskt. Och ungdomsbrottsligheten ökar, det gör den visst det! Mindre utrymme, om ens något, ges till statistiken som visar att bostadsinbrotten minskat kontinuerligt under en 25-årsperiod, för de ökade ju med fyra procent mellan år 2002 och 2003! 


\section{Referenser}

Blixt, M (2001) Bilbrott. I: Brottsutvecklingen i Sverige1998-2000. BRÅ-Rap port 2001:10. Stockholm: Fritzes.

BRÅ (2000) Barnmisshandel. En kartläggning av polisanmäld misshandel av små barn. BRÅ-Rapport 2000:15. Stockholm:Fritzes.

BRÅ (2003) Stöld, våld och droger bland ungdomar $i$ årskurs nio. Resultat från fyra självdeklarationsundersökningar. BRÅ-Rapport 2003:5. Stockholm: Fritzes.

Cohen, L \& Felson, M 1979): Social Change and Crime rate trends: A Routine Activity Approach. American Sociological Review, 44: 588-607.

Janson, S (2001) Barn och misshandel - en rapport om kroppslig bestraffning och annan misshandel $i$ Sverige vid slutet av 1900-talet. Rapport utarbetad på uppdrag av Kommittén mot barnmisshandel, SOU 2001:72. Stockholm: Fritzes.

Janson, S (2004). Arhundradets attitydförändring. Artikel i Brottsförebyggande rådets tidskrift Apropå, nr 1, 2004.

Korsell, L (2001): Ekonomisk brottslighet. I: Brottsutvecklingen i Sverige19982000. BRÅ-Rapport 2001:10. Stockholm: Fritzes.

Korsell, L (2001b) Miljöbrott. I: Brottsutvecklingen i Sverige1998-2000. BRÅRapport 2001:10. Stockholm: Fritzes.

Kühlhorn, E (2001) Misshandel. I: Brottsutvecklingen i Sverige1998-2000.BRÅRapport 2001:10. Stockholm: Fritzes.

Lööw, H (2001) Hets mot folkgrupp. I: Brottsutvecklingen i Sverige1998-2000. BRÅ-Rapport 2001:10. Stockholm: Fritzes.

RSV (2003) Skatter i Sverige. Skattestatistisk årsbok 2003. Stockholm:Fritzes.

Rying, M (2003) Dödligt våld $i$ kriminalstatistiken. Brottsförebyggande rådet. Stencil.

SOU 2001:72. Barnmisshandel. Att förebygga och åtgärda. Slutbetänkande av Kommittén mot barnmisshandel. Stockholm:Fritzes.

Svensson, B (1984) Kriminalitetsutvecklingen i Sverige 1950 - 1982 -tendenser och förklaringar. NTfK, 1984, nr 2:109-125.

Westfeldt, L (2001): Brott och straff $i$ Sverige och Europa. Stockholms universitet, Kriminologiska institutionen. Akademisk avhandling.

Adress:

Brottsförebyggande Rådet

Box 1386

SE - 11193 Stockholm

jan.andersson@bra.se 